\title{
Organização do estoque com aplicação do Kaizen 3P e da Curva ABC: um estudo de caso em uma indústria têxtil
}

\author{
RESUMO
}

Paula Oliveira Cabral Chagas pcabral@hotmail.com
Faculdade Farias Brito (FFB), Três Faculdade Farias Brito (FFB),
Lagoas, Mato Grosso do Sul, Brasil

Mauricio Johnny Loos mauricioloos@hotmail.com Faculdade Farias Brito (FFB), Três Lagoas, Mato Grosso do Sul, Brasi
A proposta deste artigo é analisar a importância da gestão de estoques e de armazenagem através dos critérios de organização dos SKUs (Stock Keeping Unit - Unidade de Manutenção de Estoque) com base na classificação da curva ABC (Activity Based Costing Sistema de Custeio) de cada produto. A aplicação desta proposta na empresa estudada teve como objetivo assegurar que os itens de maior demanda estivessem sempre nos níveis de armazenagem que não necessitem do uso de empilhadeiras e escadas para a separação dos produtos (picking). Para este estudo, diversos projetos de melhorias foram utilizados, como o Kaizen de 3P (Production Preparation Process - Processo de Preparação da Produçãoł, que visa o aumento de produtividade através de estudos de layouts enxutos, reclassificação da curva $A B C$, adequação dos unitizadores para armazenamento dos produtos com demandas variadas e adequação das alturas das posições dos portapallets. Para estes projetos de melhoria foram coletadas informações do sistema ERP da empresa e de documentos internos como o projeto da fábrica. Os resultados do trabalho mostram uma reorganização dos estoques, gerando disponibilidade de espaço interno, facilitando a realização de inventários, bem como aumentando o nível de serviço.

PALAVRAS-CHAVE: Indústria Têxtil. Gestão de Estoques. Kaizen 3P. Curva ABC. 


\section{INTRODUÇÃO}

Os acontecimentos ocorridos na economia brasileira na década de 1990 tiveram impactos definitivos no setor têxtil. Na década de 2000 segue-se com o processo de modernização, tanto do parque fabril quanto das formas de gestão empresarial, visto que o país passa a se destacar nos mercados externos, ganhando novos consumidores.

Conforme Andrade (2006, p. 45):

Em paralelo ao processo de modernização do parque fabril, pela importação de máquinas de eficiência superior, busca-se melhorar o desempenho dos resultados por intermédio de uma gestão conjunta de toda a cadeia de suprimentos, estabelecer uma produção de forma coordenada entre os diversos segmentos que compõe a cadeia produtiva têxtil com o objetivo de reduzir as ineficiências e criar melhores condições para suportar as pressões da forte concorrência internacional (ANDRADE, 2006, p. 45).

Nos dias de hoje, a abertura dos mercados e o consequente aumento da concorrência fez com que as tecnologias de produção se disseminassem e as demandas se voltassem para uma maior variedade dos produtos em quantidade menores.

A empresa foco deste estudo, com o aumento da importação de produtos, teve a necessidade de aumentar a equipe da Logística Interna e adquirir novas paleteiras elétricas, porta-pallets e unitizadores, a fim de suprir a nova demanda do setor, e o aumento de atividades como o acolhimento desses tecidos no sistema e a atividade de armazenagem.

A proposta deste artigo é analisar a importância da gestão de estoques e de armazenagem através dos critérios de organização dos SKUs (Stock Keeping Unit Unidade de Manutenção de Estoque) com base na classificação da curva ABC (Activity Based Costing - Sistema de Custeio) de cada produto. A aplicação desta proposta na empresa estudada teve como objetivo assegurar que os itens de maior demanda estivessem sempre nos níveis de armazenagem que não necessitem do uso de empilhadeiras e escadas para a separação dos produtos (picking). Justifica-se este trabalho pela necessidade da empresa em atender o cliente dentro do prazo, separando todos os produtos comprados por ele, sem correr o risco de ter algum produto não localizado pelos erros de mapeamento ou falta de organização dos estoques, bem como pela importância do setor têxtil para a economia brasileira.

Este trabalho adota uma pesquisa como um estudo de caso. Para aplicação do estudo, foram dedicados alguns dias de um grupo de colaboradores da empresa estudada. Estes compunham a equipe do Kaizen 3P (Production Preparation Process - Processo de Preparação da Produção) e que ficaram em uma sala de treinamento para discussão sobre as oportunidades de melhorias levantadas, no setor analisado e as possibilidades de projetos a serem apresentados à diretoria. Alguns métodos foram utilizados para levantamento das informações, como a cronoanálise, visita ao local estudado, filmagens, fotografias e entrevista com o engenheiro civil responsável pelo projeto da fábrica. Os resultados do trabalho mostram uma reorganização dos estoques, gerando disponibilidade de espaço interno, facilitando a realização de inventários, bem como aumentando o nível de serviço. 
Para cumprir seus objetivos, o trabalho primeiramente estabelece o referencial teórico, seguido pelos procedimentos metodológicos adotados, apresentação dos resultados e a conclusão do estudo de caso.

\section{REVISÃO DA LITERATURA}

Nesta seção é apresentada uma revisão da literatura sobre Indústria Têxtil, Produção Enxuta e Administração de Materiais, para posteriormente realizar a análise dos dados do caso a ser apresentado.

\section{EVOLUÇÃO DA INDÚSTRIA TÊXTIL}

Na década de 1990 ocorreram muitas mudanças de âmbito econômico no Brasil, entre elas a liberação às importações e a criação do Plano Real. Essas mudanças trouxeram um crescimento atípico na concorrência que fez com que as empresas nacionais buscassem inovações em seus produtos e processos produtivos, e o setor têxtil brasileiro foi o que mais sentiu com essa nova concorrência visto que seu maquinário estava muito obsoleto para seus produtos competirem com os produtos asiáticos.

Com o novo mercado buscando mais qualidade, inovação, agilidade e flexibilidade, a indústria têxtil brasileira precisou inovar o seu processo produtivo e para atender à essa demanda mais exigente, buscou altos volumes de investimentos, como aquisição de teares mais modernos e produtivos, como o tear a jato de ar, a jato de água e os teares de pinça e de projétil. Os teares a jatos de ar e de água possuíam, em 1999, uma idade média de 20 vezes menor que os teares de lançadeira (GORINI, 2000).

Diante disso, Kon et al. (2009) afirmam que na década de 1990 os investimentos na indústria têxtil foram cerca de US\$ 5,5 bilhões somente em importação de equipamentos, distribuídos nos setores de fiação, tecelagem, malharia e beneficiamento. Como mostra o gráfico 1, a balança comercial do setor têxtil desde a abertura às importações teve um crescimento contínuo na importação e um dos fatores atuais é a dificuldade de competir com a mão de obra asiática e os altos valores dos impostos brasileiros.

Nas palavras de Kon et al. (2009, p. 11):

A indústria têxtil do Brasil nasceu ainda no período colonial, desenvolveu-se acentuadamente a partir do início do século XX e encontrou maturidade na década de 1940, quando chegou a ser considerada um setor dinâmico de uma economia subdesenvolvida. Isso se verificou tendo em vista ter alcançado uma sólida estrutura que lhe conferiu a posição de segundo lugar na produção têxtil mundial, e de exportar para grande parte do mundo, por ocasião da Segunda Guerra Mundial (KON et al., 2009, p.11).

Face a isto, o polo industrial têxtil do Brasil, no momento da abertura às importações, detinha $85 \%$ da produção concentrada nos municípios de Santa Bárbara, Nova Odessa, Sumaré e Americana e, procurando diminuir seu custo de produção, uma das ações tomadas foi o deslocamento do parque industrial para estados que ofereciam incentivos fiscais através de projetos de desenvolvimento e capacitação da mão de obra local em comuns com o governo (KON et al., 2009). 
Gráfico 1 - Balança Comercial do Setor Têxtil (exceto fibra de algodão)

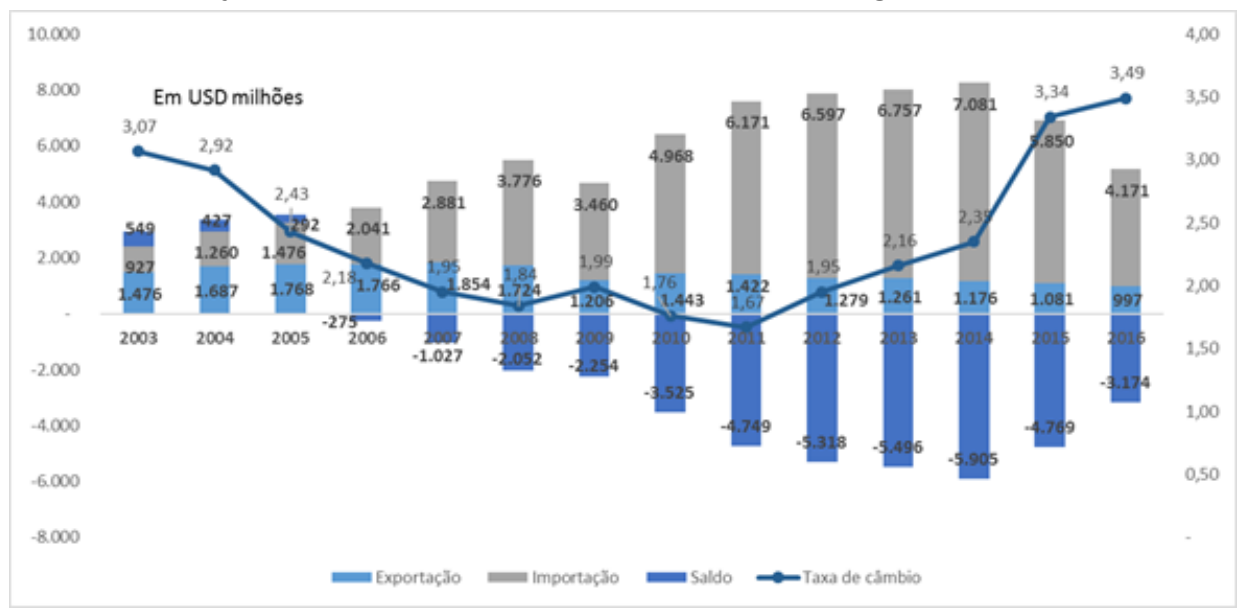

Fonte: Associação Brasileira da Indústria Têxtil e de Confecções - ABIT. Adaptado pela autora.

No final da década de 1990 a indústria têxtil aparece como o sétimo maior produtor mundial e o terceiro como produção de malharia. Segundo dados do Instituto de Estudos e Marketing Industrial - IME - hoje o Brasil ocupa o quinto lugar no ranking mundial, responsável por $2,4 \%$ da produção têxtil mundial.

\section{PRODUÇÃO ENXUTA}

Com o fim da segunda guerra mundial, o Japão encontrou na necessidade de se reerguer um meio de passar por grandes mudanças em sua estrutura organizacional, baseando-se, principalmente, nas filosofias do gerenciamento da produção, como abordado por Teixeira e Doriguel (2015). A empresa Toyota, unindo as diversas filosofias de gestão que já existiam, criou o Sistema Toyota de Produção - STP, conhecido também como Lean Manufacturing ou Produção Enxuta.

Simbolizado na figura 1 como a Casa da Toyota, o STP visa o aumento da produtividade através da eliminação e/ou redução dos sete desperdícios, sendo eles: superprodução, tempo de espera, movimentação excessiva, processo inadequado, retrabalhos, estoques e transporte excessivo (já se contabiliza o oitavo desperdício como sendo o desperdício intelectual, uma mão de obra especializada mal aproveitada).

O Lean Manufacturing busca, através de melhoria contínua, a resolução do problema pela causa raiz, reduzir ou eliminar as atividades que não agregam valor, redução de custos, garantia da qualidade, defeito zero, aumento de produtividade, processos puxados e flexibilidade na sua produção.

Como citado por Silva et al. (2018, p. 6), "o sistema Lean possui objetivos que se baseiam no Sistema Toyota de Produção, tendo um controle desde o início da cadeia, com o pedido do cliente, até a entrega do produto final, para que o tempo dos processos seja reduzido". 
Figura 1 - Casa da Toyota

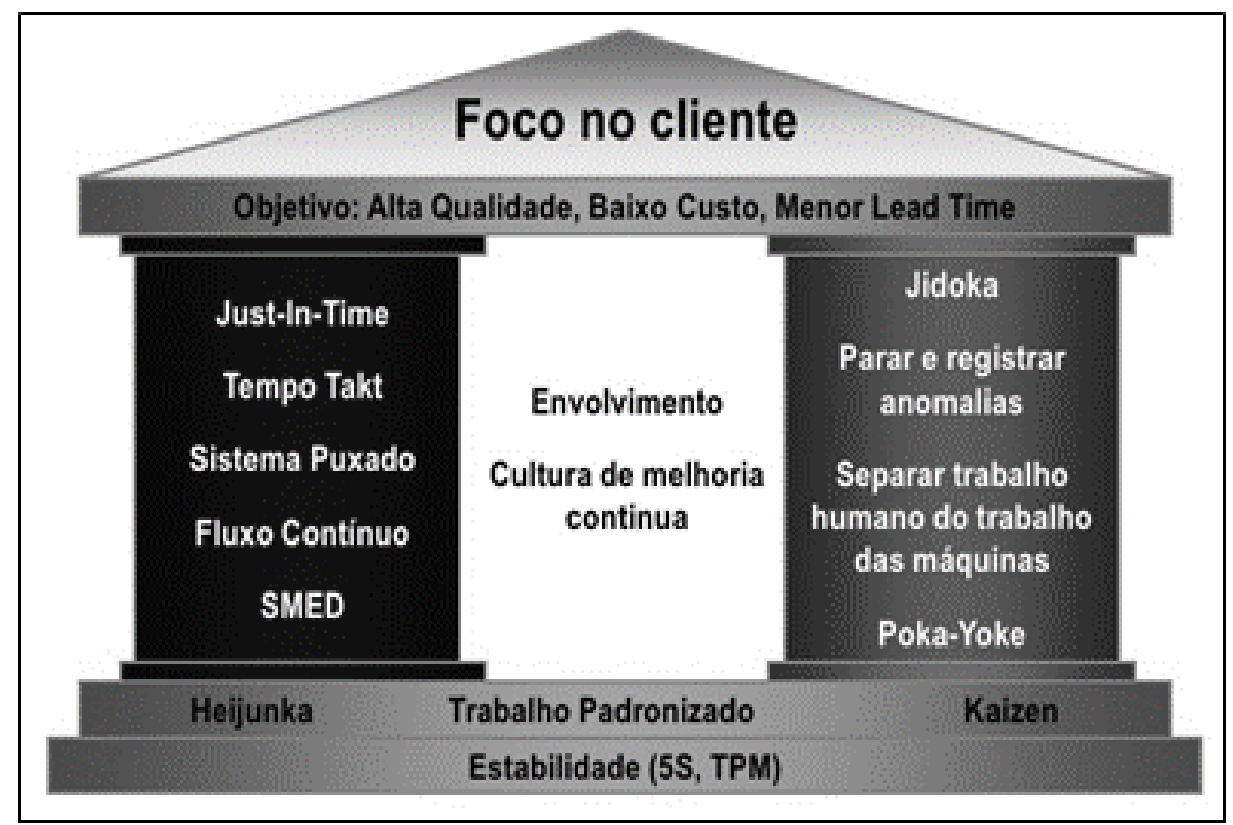

Fonte: Descomplicando o Lean. http://www.descomplicandolean.com.br/leanmanufacturing/.

Como citado por Ribeiro et al. (2016):

"Um dos sistemas de gestão mais utilizados atualmente é a produção enxuta, que tem como premissa a busca por eliminação contínua dos desperdícios. Mais do que identificá-los, é preciso promover as mudanças necessárias para eliminálos ou reduzi-los".

Para a redução e/ou eliminação dos desperdícios, um dos meios para isso é através da filosofia Kaizen (Kai - Mudança / Zen - Para Melhor), que, segundo Teixeira e Doriguel (2015), "tem como conceito a melhoria contínua de um fluxo completo de valor ou de um processo individual, a fim de se agregar mais valor com menos desperdício".

É importante lembrar que mesmo com todas as ferramentas do lean disponíveis para qualquer empresa adotar, todas as pessoas da empresa precisam se envolver, principalmente a alta diretoria, pois sem o apoio dela muitas melhorias serão canceladas ainda em fase de planejamento. "Tais ferramentas auxiliam na identificação e eliminação de desperdícios, melhoria da qualidade, redução de tempo e custo de produção, visando a satisfação das necessidades dos clientes", afirma Silva et al. (2018, p. 5). A equipe operacional também precisa receber treinamento para entender o motivo do uso de determinadas técnicas lean e poder replicar a cada oportunidade de melhoria que enxergarem na rotina do trabalho.

\section{ADMINISTRAÇÃO DE MATERIAIS}

A Revolução Industrial, no século XIX, modernizou os processos produtivos que antes eram artesanais, o que aumentou a concorrência, a importância do 
setor de Compras e a relevância em se ter estoques. Neste período, a administração de materiais passa a ter destaque, pois, o planejamento passa a ser mais estratégico e menos caseiro. A Administração de Materiais se preocupa em planejar para ter o produto no tempo oportuno, na quantidade necessária, na qualidade requerida e pelo menor custo.

Como parte integrante da logística o planejamento, compras, produção e a distribuição, são tratados na a administração de materiais que hoje no Brasil ainda é vista como a logística integrada da empresa, o que deixa de reduzir custos e/ou ganhar novos mercados por não tratar esta atividade como parte do planejamento estratégico em logística da empresa.

Para Zamcopé et al. (2010), "a Logística vem apresentando contínua evolução desde a Segunda Guerra Mundial, sendo hoje considerada elemento fundamental na formulação das estratégias das organizações". Hoje, a Logística procura eliminar do processo tudo que não agrega valor para o cliente, através de melhoria contínua em seus processos, uma vez que a Logística é uma atividade que não agrega valor, mas necessária, sob o ponto de vista de muitos autores.

Em situações em que uma empresa deseja lançar um novo produto, ela deve analisar também informações como tipo de unitizador adequado para o novo SKU, como será armazenado, tipo de embalagem, se será necessária a compra de novos equipamentos, aumento de mão de obra, tudo isso, muitas vezes, não é tido como premissas nas reuniões estratégicas de lançamentos de produtos.

Como sendo uma das áreas mais prósperas na busca de redução de custos e aumento de competitividade, a logística é considerada elemento chave para a estratégia competitiva da organização e, com base nisso, a gestão de estoques de uma empresa deve ser eficiente, considerando todas as particularidades de seus produtos.

Os desperdícios de transporte e movimentação em excesso nunca agregam valor ao produto, portanto, deve-se buscar sempre sua eliminação pois significa que não há um planejamento quanto ao mapeamento dos produtos. $\mathrm{O}$ cliente não paga pela procura do item no estoque e por essa razão a importância de uma gestão de armazenagem eficiente.

Como esclarece Corrêa e Corrêa (2004), "os estoques, em geral, são uma das maiores preocupações, não só dos gestores de operação, mas também:

- Gestores financeiros: que se preocupam com a quantidade de recursos financeiros que os estoques 'empatam' e seus correspondentes custos;

- Gestores comerciais: que se preocupam com o prejuízo no atendimento aos clientes que uma possível indisponibilidade de produtos acabados pode acarretar;

- Gestores Fabris: que se preocupam com a onerosa ociosidade de sua fábrica, que uma possível falta de matéria-prima pode acarretar".

Para Grando et al. (2018, p. 3):

(...) os estoques permitem certas economias na produção e regulam sua velocidade de fluxo, ou seja, em determinados períodos, a produção não acompanha a demanda, havendo a necessidade de estoques de produtos acabados para acompanhar estes picos, em 
outros momentos a entrega de matérias-primas não acompanha a produção, justificando-se assim a necessidade de estoques, da mesma forma que quando a demanda fica abaixo das expectativas, os estoques tanto de produtos acabados como de matérias-primas também fazem parte da realidade das empresas (GRANDO et al., 2018, p. 3).

Como ressalta Dos Santos (2006), "com o crescente número de itens com diferentes padrões de demanda e características específicas, a complexidade na administração de materiais aumenta devido à necessidade de controle diferenciado" e por essa razão que a gestão de estoques de produtos de baixa demanda apresenta algumas particularidades. Os custos de aquisição de SKUs de baixa demanda em geral são mais altos, visto que a compra é feita de baixo volume e o giro dos estoques em geral é mais baixo, porém pode entrar um pedido de alto volume, fora da previsão, e não ter estoque.

O estoque armazenado em um depósito significa retenção de capital ocioso e oportunidades de lucro não realizadas, por isso a necessidade de se fazer a manutenção dos estoques a fim de manter o equilíbrio entre a demanda e oferta. Para as empresas que possuem grande parte dos estoques com produtos importados, ainda têm as dificuldades que envolvem as "flutuações cambiais, influências no comportamento e métodos de compra, datas comemorativas, crises de abrangência global e outros acontecimentos, que afetam diretamente a procura pelos produtos, assim como sua produção e fornecimento", como afirmam Gavioli et al. (2009).

Os custos de armazenagem e movimentação de produtos podem absorver uma boa parte das despesas logísticas de uma empresa. Por este lado, verifica-se a necessidade da correta administração destes aspectos para o objetivo final de redução de custos através da melhoria nos aspectos logísticos da empresa. De acordo com POCINHO (2013) apud Bittencourt e Accioly (2017, p. 2) "as atividades de armazenagem quando bem desempenhadas podem aumentar sua produtividade e eficiência, consequentemente reduzindo o tempo das operações e os prazos de e entrega, diminuindo os custos e aumentando a satisfação do cliente".

Para Lima (2000, p. 1):

Uma das principais características da logística moderna é sua complexidade operacional. Aumento da variedade de produtos entregas mais frequentes, menores tempos de atendimento, menor tolerância a erros de separação de pedidos e pressões para redução dos níveis de estoque, são alguns drivers da complexidade (LIMA, 2000, p. 1).

$\mathrm{O}$ autor acima citado refere-se ainda sobre a necessidade de se ter um sistema de custeio relacionado à armazenagem visto, que os custos voltados para esta atividade vêm aumentando sua participação no custo total operacional, uma vez que a armazenagem de produtos vem se destacando a cada ano. Com o $e$ commerce (comércio eletrônico) em alta demanda, o processo de armazenagem necessita uma capacitação maior das pessoas envolvidas na gestão de estoques e armazenagem, principalmente na atividade de separação e reposição através do FIFO (First In First Out - primeiro que entra, primeiro que sai), o qual determina a reposição do picking, nível de acesso fácil para o separador, com os produtos com datas de produção mais antigas. 
Para Santos (2014) apud Bittencourt e Accioly (2017, p. 2) "a principal atividade logística da maioria dos armazéns é o picking, pois é uma das mais dispendiosas e trabalhosas, sendo que na maioria dos casos os custos podem chegar a $50 \%$ do total dos custos do armazém, portanto otimizar e melhorar esta atividade é uma forma de reduzi-los e atender rapidamente o pedido do cliente".

Uma das formas de se analisar e controlar o estoque é através da curva $A B C$ (Activity Based Costing - Sistema de Custeio), pois ela permite identificar os produtos que justificam atenção e tratamentos adequados em relação a sua administração. Este método, também conhecido pelo Diagrama de Pareto ou curva 80-20, prioriza os produtos que trarão maiores benefícios à empresa ou os produtos que a empresa precisa ter um tratamento especial, por exemplo.

Figura 2 - Curva $A B C$

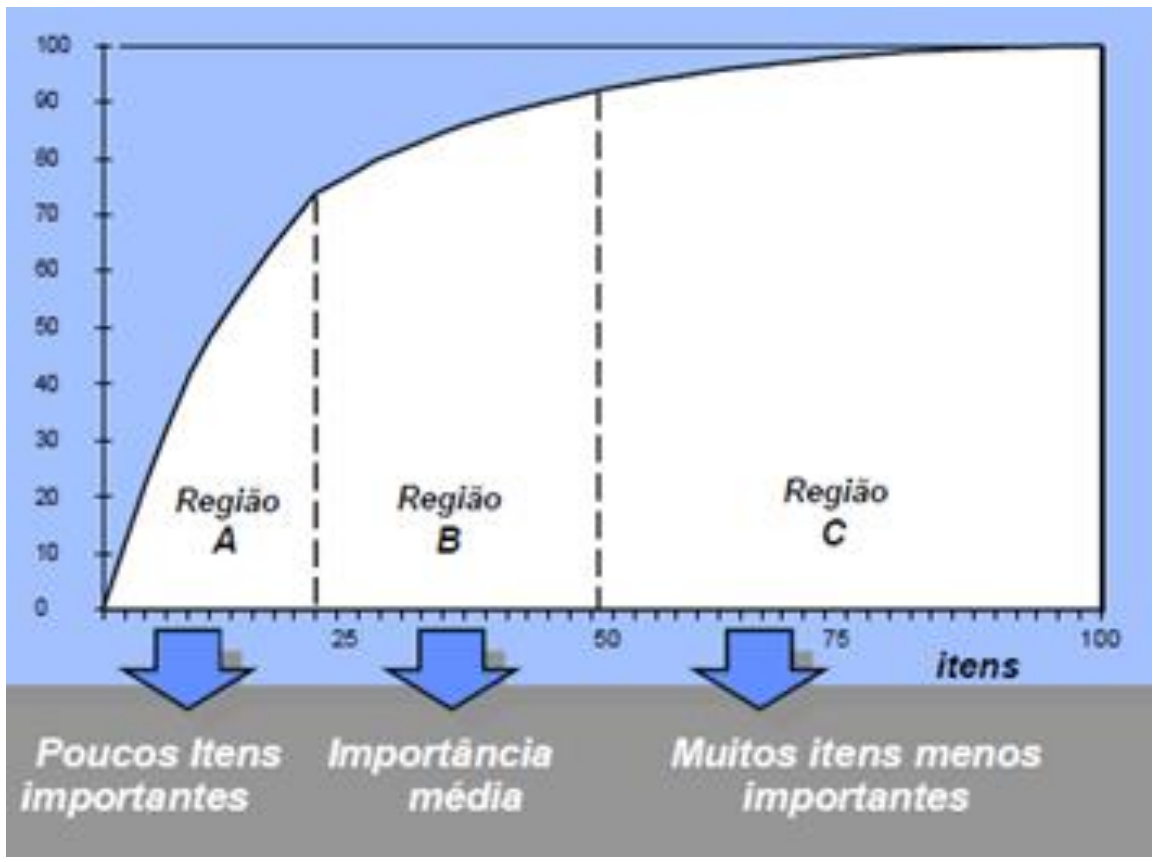

Fonte: Corrêa, Gianesi e Caon (2001).

A curva $A B C$, como ilustrada na figura 2, pode fornecer informações como, por exemplo, os poucos produtos que representam o maior volume de faturamento da empresa, produtos de alto consumo interno, mas de custo baixo ou o contrário, produtos de baixo consumo, mas que muitas vezes são importados e por este motivo precisam de uma atenção maior devido à taxa cambial.

\section{PROCEDIMENTOS METODOLÓGICOS}

O estudo de caso foi aplicado em uma empresa têxtil, a qual possui seu parque industrial no estado do Mato Grosso do Sul, e passou por todas as modificações de política econômica da década de 1990. Com o aumento da importação e redução da produção interna, a empresa está passando por uma reorganização dos depósitos a fim de manter atualizados os SKUs com maior demanda sempre no fácil acesso para picking, reduzindo os desperdícios de transporte, movimentação e espera para atendimento do cliente. 
A Logística Interna foi o setor escolhido para aplicação das propostas de melhoria deste estudo, a qual possui muitas oportunidades de melhoria em busca de redução de custo, uma vez que este setor tem crescido continuamente por conta do alto volume de importação e criação de novos artigos. O objetivo deste estudo é assegurar que os itens de maior demanda estejam sempre em acesso facilitado para a realização do picking, através de um rearranjo do layout dos porta-pallets e adaptação dos unitizadores, contribuindo com o aumento de produtividade da equipe de separação, armazenagem e abastecimento a fim de manter e aumentar o nível de atendimento ao cliente.

A empresa possui artigos de produção própria e importados, tendo em seu estoque um total de $2.900 \mathrm{SKUs}$, aproximadamente, para armazenar nas 5.680 vagas existentes. Com o aumento da importação e redução da produção interna, a empresa já está passando por uma reorganização dos depósitos com o propósito de reduzir os desperdícios de transporte, movimentação e espera para atendimento do cliente. A figura 3 mostra uma ilustração do fluxo do processo metodológico adotado neste estudo de caso.

Figura 3 - Fluxo do Processo Metodológico

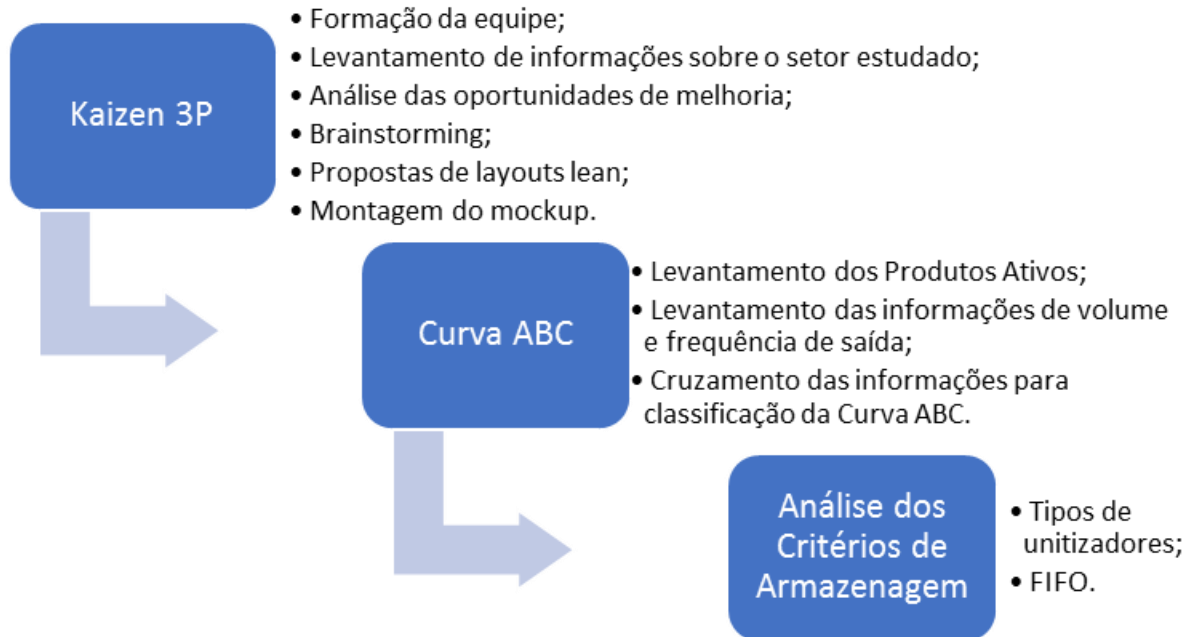

Fonte: Elaborado pelo autor.

\section{KAIZEN 3P}

Segunda Corrêa e Corrêa (2011) apud Aguiar e Júnior (2018, p. 2) "um bom projeto de arranjo físico pode visar tanto eliminar atividades que não agregam valor como enfatizar atividades que agregam valor, como por exemplo: minimizar custos de manuseio e movimentação interna, utilizar espaço físico de forma eficiente, facilitar a comunicação entre as pessoas envolvidas na operação, reduzir tempos de ciclo dentro da operação, facilitar a entrada e saída e movimentação dos fluxos.".

Para dar início às melhorias deste setor, foi realizado o Kaizen 3P (Production Preparation Process - Processo de Preparação da Produção), o qual, 
como citado por Torres Junior (2005), "trata-se da designação de um método para desenhar processos de produção lean, ou, simplesmente, obter soluções aos problemas de fluxo de produção, tendo como consequência a radical inovação do estado atual".

Como afirma Torres Junior (2005), "as empresas praticantes do 3P divulgam economia de 30 a $50 \%$ em investimentos de capital e 20 a $40 \%$ de custos de manufatura". Este método propicia a descoberta de soluções que somente são possíveis com a avaliação nos locais de estudo, a troca de conhecimento entre as pessoas e experimentação na prática ou simulações.

Essa ferramenta trabalha com uma quantidade mínima de 7 alternativas de layouts para o setor estudado. Com esses arranjos desenhados uma avaliação é realizada através de um formulário, conforme figura 3. A pontuação é feita tendo como base uma nota 5 como atendendo plenamente aos requisitos lean em questão e nota 1 como não atendendo ao requisito. Com todos os layouts analisados e pontuados, os 3 melhores são simulados para conceber uma visão dos equipamentos e layouts. As premissas para o novo arranjo físico são: reduzir desperdícios de movimentação, aumentar produtividade, reduzir esforço físico, melhorar a ocupação da capacidade de armazenagem e melhorar a qualidade dos produtos. Como afirmado por Neumann e Scalice (2015) apud Aguiar e Júnior $(2018$, p. 5) "o layout de qualquer empresa é o resultado final de uma análise de arranjos físicos propostos após decisões relacionadas à produção, produto e processos terem sido tomadas".

No depósito de estoque acabado, área física da Logística onde o kaizen 3P foi aplicado, antes do crescimento da empresa, havia um setor produtivo e por este motivo o depósito não foi projetado com visão de processos logísticos. Além desta observação levantada durante as pré-análises do 3P, os porta-pallets deste depósito não eram padronizados, não tinham seus níveis de armazenagem com altura padrão, os corredores entre os porta-pallets não tinham largura segura para movimentação das empilhadeiras e apenas o nível A era de picking, mas que estava ocupado nas 16 filas das 24 que existem com artigos que não tinham como serem paletizados e, por este motivo, estes artigos ficavam soltos nas vagas do nível A de armazenagem, ocupando as 2 vagas das 2 filas do conjunto de porta-pallets.

Feito o levantamento dos problemas da área, a equipe do 3P, composta por colaboradores internos de diferentes setores, se reuniu para discutir as possibilidades de projetos de melhoria, visando saná-los parcialmente ou por completo, dependendo do grau de complexidade dos projetos. Alguns pontos foram levantados durante um brainstorming (chuva de ideias, discussão sobre as possibilidades) realizado na equipe, como a possibilidade de adequação dos porta-pallets para ganho de mais posições no picking; ajuste da largura dos corredores para movimentação segura dos operadores de empilhadeiras; abertura de um corredor nos porta-pallets para passagem da mangueira do hidrante, visto que os armários das mangueiras se localizavam dentro de uma das vagas do picking; troca dos pallets de madeira pelos unitizadores metálicos; possibilidade de derrubar a parede que divide o depósito e a doca; unificação da sala da coordenação da expedição, faturamento e logística, dentre outros pequenos levantamentos. 
Após a realização do brainstorming, a equipe desenhou 7 layouts diferentes que envolvessem todas as possibilidades de melhoria sem, neste momento, olhar custo de projeto ou aprovação da direção. Em sequência, estes 7 layouts foram analisados e pontuados no relatório demonstrado na figura 4.

Figura 4 - Relatório de Pontuação dos Layouts.

\begin{tabular}{|c|c|c|c|c|c|c|c|c|c|c|c|c|c|c|c|c|c|}
\hline \multicolumn{18}{|c|}{ AVALIAÇÃO DE ALTERNATIVAS } \\
\hline \multicolumn{7}{|c|}{$\begin{array}{l}\text { Descrição da Peça: } \\
\text { No Operação }\end{array}$} & \multicolumn{6}{|c|}{ Resp:: } & \multicolumn{5}{|l|}{ Data: } \\
\hline & Requisitos do Sistema Lean & Peso & 1 & Mult. & 2 & Mult. & 3 & & Mult. & 4 & Mult. & 5 & 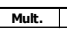 & 6 & Mult. & 7 & Mult. \\
\hline 1 & Atender a variacão do takt time & 5 & & 0 & & & & & 0 & & 0 & & 0 & & 0 & & \\
\hline 2 & Huxo de peca única & 2 & & 8 & 4 & 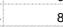 & & 4 & 8 & & 8 & 4 & 8 & 3 & 6 & & \\
\hline 3 & Envolvimento do operador (Fabricação) & 2 & & 4 & & 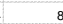 & & 4 & 8 & & 8 & 4 & 8 & 4 & 8 & & \\
\hline 4 & Descarregamento Automático & 1 & & 4 & 2 & 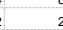 & & 2 & 2 & & 3 & ${ }_{3}^{4}$ & 3 & $3^{4}$ & 3 & & 4 \\
\hline 5 & Carregamento & 1 & & 3 & 3 & s. & & 2 & 2 & & 3 & 3 & 3 & 3 & 3 & & \\
\hline 6 & Poka-yoke (a prova de erros) & 5 & & 20 & & 20 & & 4 & 20 & & 20 & 4 & 20 & 4 & 20 & & \\
\hline 7 & Investimento minimo & 5 & & 5 & & 15 & & 4 & 20 & & 10 & 2 & 10 & 2 & 10 & & \\
\hline 8 & Operacáo que agrega valor & 5 & & 20 & 2 & 10 & & 2. & 10 & 3 & 15 & 3 & 15 & 3 & 15 & & 15 \\
\hline 9 & Troca rápida & 5 & & 20 & & 20 & & 4 & 20 & & 20 & 4 & 20 & & 20 & & \\
\hline 10 & Simplicidade Manufatura & 5 & & 15 & 3 & 15 & & 3 & 15 & 3 & 15 & 3 & 15 & 3 & 15 & & 15 \\
\hline 11 & Processo conhecido & 5 & & 15 & 3 & 15 & & 3 & 15 & 3 & 15 & 3 & 15 & 3 & 15 & & 15 \\
\hline 12 & Jidoka & 5 & & 20 & & 20 & & 4 & 20 & 4 & 20 & 4 & 20 & 4 & 20 & & 20 \\
\hline & Operaçao Limpa / Meio Ambiente & 2 & & 8 & & t. & & 3 & 6 & & 8 & 4 & 8 & & 8 & & \\
\hline \multirow[t]{2}{*}{14} & Ergonómico e seguro & 5 & & $\begin{array}{l}4 \\
4\end{array} \quad 20$ & & 20 & & 3 & 15 & 3 & 15 & 4 & 20 & 3 & 15 & & 20 \\
\hline & Total & & & 166 & & 164 & & & 161 & & 160 & & 165 & & 158 & & \\
\hline
\end{tabular}

Fonte: Relatório de uso interno da empresa estudada

Com as propostas de layouts desenhadas e a avaliação já pontuada, as três propostas com maiores notas foram tituladas como propostas lean e essas propostas foram apresentadas à diretoria para avaliação e primeira aprovação. As propostas que demandariam um custo maior, como reformas prediais no depósito e adequação da orientação dos porta-pallets foram descartadas visto que, além de um alto custo, levariam muito tempo para cumpri-las. O layout aprovado pela direção tinha como proposta a adequação da altura dos níveis de armazenagem para adaptar o nível B (nível acima do nível A) como picking, mudança dos unitizadores para maior capacidade de armazenagem e facilitação na separação (consequente redução do seguro contra incêndio, já que o unitizador de ferro é mais seguro que o pallet de madeira), organização dos produtos acabados e adequação dos corredores entre os porta-pallets para movimentação segura dos operadores de empilhadeira. Para última análise, os layouts escolhidos de cada setor estudado foram projetados em mockup (modelo em escala do projeto), com dimensões proporcionais, para um melhor entendimento de como ficaria o fluxo produtivo da empresa. Junto a isto, cada layout escolhido foi projetado no programa Sketchup (software próprio para criação de modelos em 3D no computador) a fim de apresentar para gerência e diretoria uma proposta mais próxima da futura realidade da empresa, como mostrada nas figuras 5 e 6.

Em concordância com Ribeiro et al., 2016, "um arranjo físico adequado é fundamental para a eliminação das fontes de desperdício e consequente aumento da eficiência". Desta maneira, com todo o projeto desenhado, simulado na maquete, no programa Sketchup e aprovado pela direção, a equipe disparou os pedidos de orçamento para realização das adequações. 
Figura 5 - Layout superior do depósito elaborado no programa Sketchup

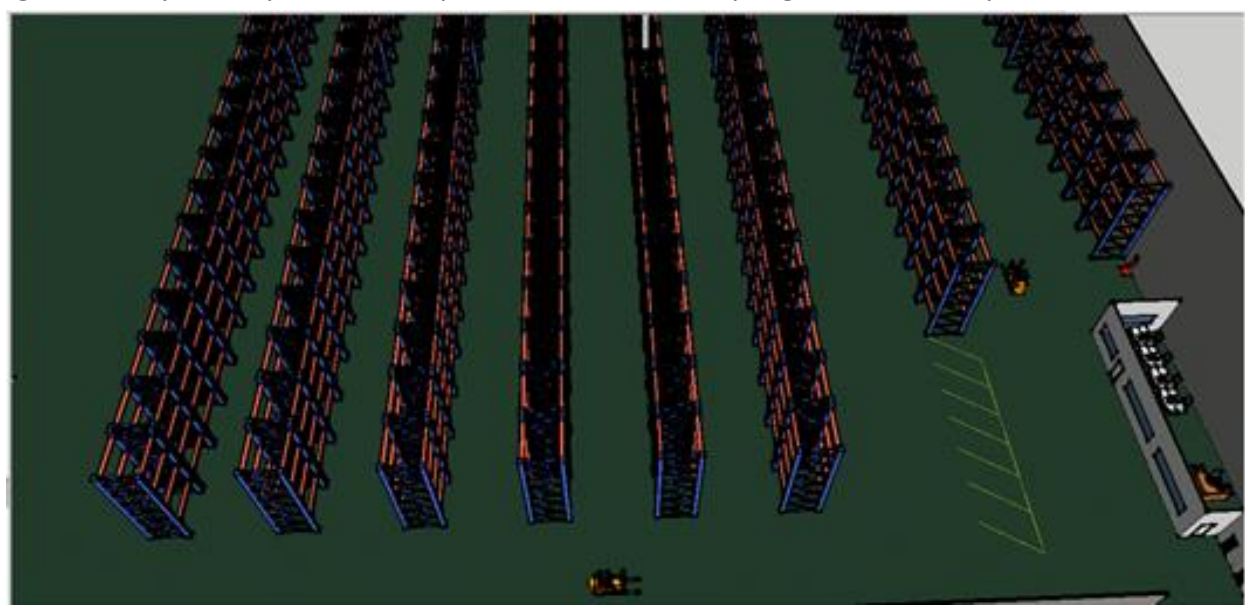

Fonte: Criado pela equipe do Kaizen 3P.

Figura 6 - Layout do depósito com o corredor para passagem da mangueira do hidrante elaborado no programa Sketchup

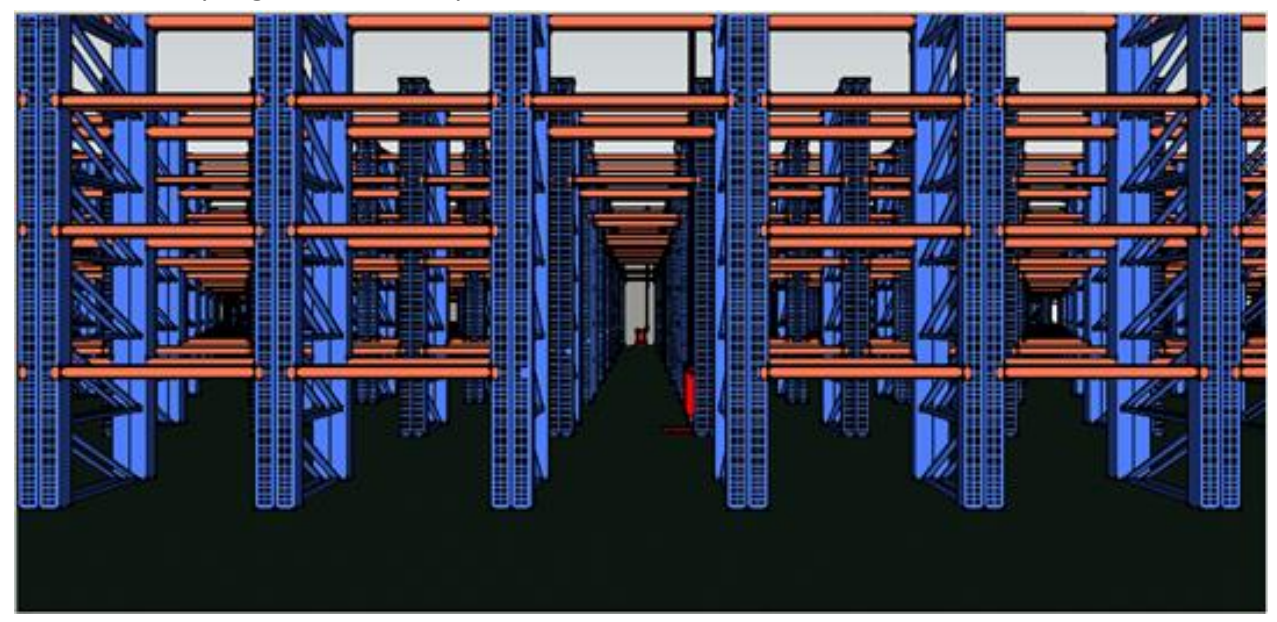

Fonte: Criado pela equipe do Kaizen 3P.

\section{CURVA ABC}

Como citado por Palomino et al. (2018, p. 3):

O método $A B C$ busca conhecer as reais necessidades de uma organização, ou seja, saber quais os materiais que representam o maior consumo, buscando o equilíbrio entre necessidade e disponibilidade de recurso. A partir da análise do método $A B C$ é possível planejar o suprimento dos estoques focando os itens que dentro de um todo são necessários para o funcionamento contínuos das atividades da empresa (PALOMINO et al., 2018, p. 3).

Para o início da análise da curva $A B C$ foram levantados todos os produtos acabados da empresa, rolos de tecido de $1,5 \mathrm{~m}$ de comprimento, e a situação de 
cada um deles como sendo ativo, ponta de estoque (que não produz e nem importa mais) e inativos (os produtos que estavam como ponta de estoque, mas que não possuem mais disponibilidade). Outras informações também foram necessárias, como os relatórios de volume de saída (em metros) e notas fiscais emitidas por SKU e para cada um desses relatórios uma curva $A B C$ foi criada. De acordo com (Palomino et al., 2018, p. 3) "os materiais que compõem o estoque e representam um alto nível de valor de consumo, denomina-se itens $A$. Aos materiais que representam um nível intermediário de valor de consumo, denomina-se itens de classe $B$ e os materiais que representam um nível baixo de volume de consumo, denomina-se itens de classe C." Com base nessas informações a curva $A B C$ por SKU foi reestruturada através da combinação da curva dos relatórios acima citados.

Tendo em mãos a nova curva por SKUs de uma mesma família, os artigos foram analisados se seriam agrupados por família (de acordo com a propriedade do tecido) ou se continuariam pela curva ABC de SKUs de família diferentes nos porta-pallets. Na primeira organização do depósito, feita somente pela curva $A B C$, a intenção era reduzir a movimentação e transporte já que os artigos de maior giro estariam mais próximos e no picking, visto que também não existiam vagas suficientes nesse nível para armazenar todos os SKUS. Com o tempo e com uma nova análise, agora com relatórios comerciais, foi levantado que os clientes compram produtos por família, diferenciando apenas as cores e estampas dos tecidos, logo, a equipe de separação estaria se movimentando mais em busca de todas as cores do mesmo artigo. Exemplificando, dentro da família de tecido voil, as cores branca e marfim saem mais de $20 \%$ que outras cores da mesma família e na primeira organização elas não estavam na mesma prateleira, com isso o colaborador andava mais já que o cliente havia comprado todas as cores do voil.

Foi adotado então que os artigos serão agrupados por família, mas dentro deste agrupamento será respeitada a curva $A B C$ combinada, como mostra a tabela 1. Por conta da diferente demanda entre os SKUs da mesma família, os unitizadores serão adaptados para que sejam armazenados mais de um produto diferente, aproveitando toda a capacidade do unitizador, como mostra a figura 7.

Tabela 1 - Curva ABC Combinada

\begin{tabular}{|c|c|c|c|c|c|c|c|c|c|}
\hline Produto & Volume mensal separado & $\%$ & $\%$ acumulado & ABC & Frequência de saída mensal & $\%$ & $\%$ acumulado & ABC & ABC Combinada \\
\hline voil branco & 500.000 & $39 \%$ & $39 \%$ & $\mathrm{~A}$ & 330 & $30 \%$ & $30 \%$ & $\mathrm{~A}$ & $\mathrm{AA}$ \\
\hline voil marfim & 450.000 & $35 \%$ & $73 \%$ & $\mathrm{~A}$ & 310 & $28 \%$ & $58 \%$ & $\mathrm{~A}$ & $\mathrm{AA}$ \\
\hline voil lilás & 86.000 & $7 \%$ & $80 \%$ & $\mathrm{~A}$ & 250 & $23 \%$ & $81 \%$ & $\mathrm{~B}$ & $\mathrm{AB}$ \\
\hline voil mostarda & 85.000 & $7 \%$ & $87 \%$ & $\mathrm{~B}$ & 100 & $9 \%$ & $90 \%$ & $\mathrm{~B}$ & $\mathrm{BB}$ \\
\hline voil verde & 75.000 & $6 \%$ & $92 \%$ & $\mathrm{C}$ & 50 & $5 \%$ & $95 \%$ & $\mathrm{~B}$ & $\mathrm{CB}$ \\
\hline voil rosa & 52.000 & $4 \%$ & $96 \%$ & $\mathrm{C}$ & 45 & $4 \%$ & $99 \%$ & $\mathrm{C}$ & $\mathrm{CC}$ \\
\hline voil azul & 47.000 & $4 \%$ & $100 \%$ & $\mathrm{C}$ & 10 & $1 \%$ & $100 \%$ & $\mathrm{C}$ & $\mathrm{CC}$ \\
\hline
\end{tabular}

Fonte: Criado pela equipe do Kaizen 3P, números fictícios.

Figura 7 - Unitizadores para SKUs com demandas variadas 

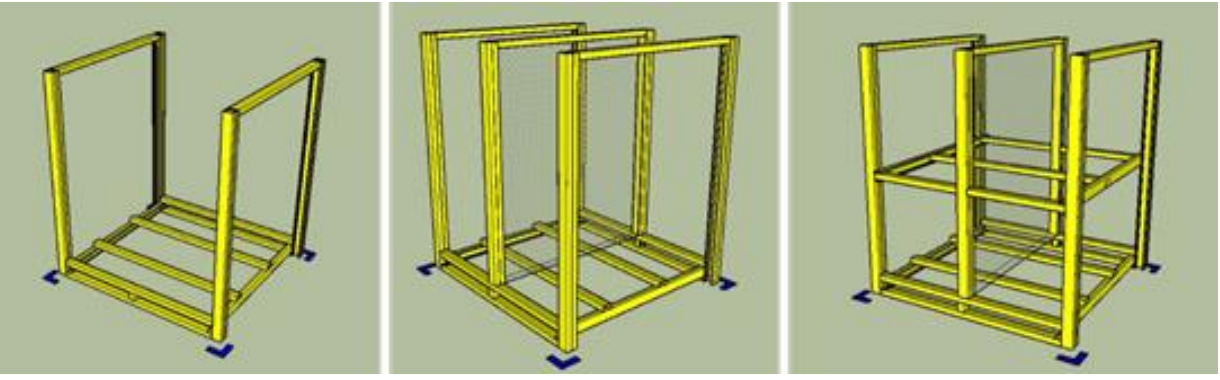

Fonte: Criado pela equipe do Kaizen 3P

Sendo assim, foi criada uma tabela de estrutura do produto com todas as seguintes informações por SKU: código do SKU, código do artigo, código da cor, descrição da unidade de negócio (decoração ou tapeçaria), descrição da família, volume e frequência de saída mensal, capacidade de armazenagem por tipo de unitizador, curva $A B C$, situação do produto (ativo, ponta de estoque ou inativo), quantidade de vagas no picking e necessidade de FIFO. A figura 8 mostra como ficou prática e rápida a atividade de reposição e separação das peças armazenadas nos unitizadores de ferro. Uma vez que o nível A de armazenamento fica desabastecido, as vagas acima descem para as vagas respectivas, deixando no picking as peças mais antigas. $\mathrm{O}$ nível $\mathrm{C}$ abastece o nível $B$ e este abastece o nível A. Como mostra a figura 8 , as duas primeiras posições da esquerda estão com o FIFO abastecido por completo (níveis $\mathrm{A}, \mathrm{B}$ e C) e, a terceira posição já corre risco de faltar produto, pois não possui o FIFO (níveis B e C) para correto abastecimento.

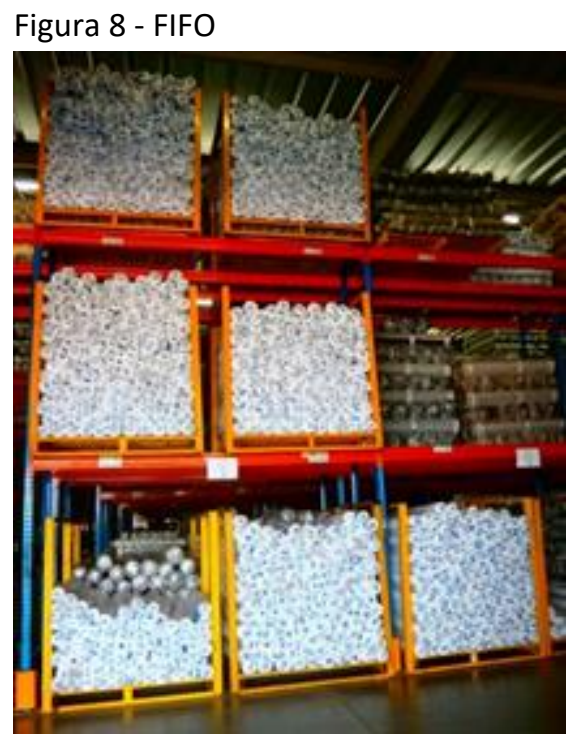

Fonte: Fotografia tirada do depósito da empresa estudada ilustrando o FIFO.

Em suma, a tabela de estrutura do produto facilitará a atualização mensal da informação e trimestral da organização do picking, mantendo, assim, sempre os artigos de maiores demandas no picking. 


\section{APRESENTAÇÃO DE DISCUSSÃO DOS RESULTADOS}

Este estudo de caso trouxe ganhos visuais, como a padronização da largura dos corredores entre os porta-pallets para $4,20 \mathrm{~m}$ de largura, visto que tinham corredores extremamente estreitos para movimentação da empilhadeira, menores de $3,5 \mathrm{~m}$, e organização do estoque através dos unitizadores que dispõem as peças em uma mesma direção, evitando a queda das peças como acontecia quando estavam paletizadas.

O depósito, com a adequação da altura dos níveis dos porta-pallets e organização dos SKUs por família, ganhou mais 720 vagas no picking (redução da altura do nível $B$ de armazenagem), conforme a figura 9, redução de movimentação de produtos e pessoas, conforme o diagrama de espaguete mostrado na figura 10 , redução de transporte, agilidade na reposição dos produtos no picking, uma vez que o FIFO foi ajustado corretamente, aumento de produtividade da equipe de separação e mais facilidade na atividade de armazenagem pelos produtos estarem agrupados por família. Com a abertura do corredor para passagem da mangueira do hidrante, ainda não colocada em prática por estarmos aguardando aprovação do Corpo de Bombeiros, será possível proporcionar maior segurança e redução de tempo e movimentação para os colaboradores durante as atividades de separação e reposição.

Figura 9 - Nível B de armazenagem com altura reduzida

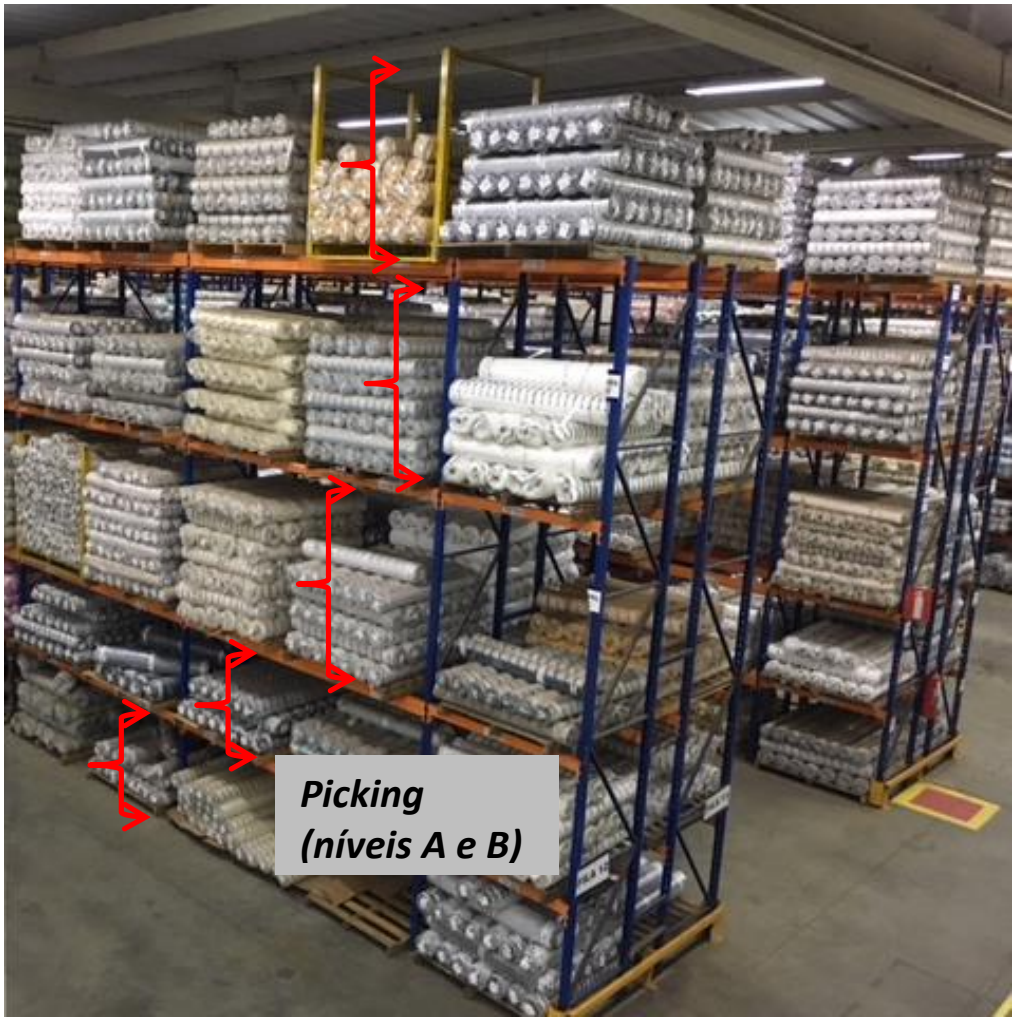

Fonte: Fotografia tirada do depósito da empresa estudada. 
Figura 10 - Diagrama de Espaguete
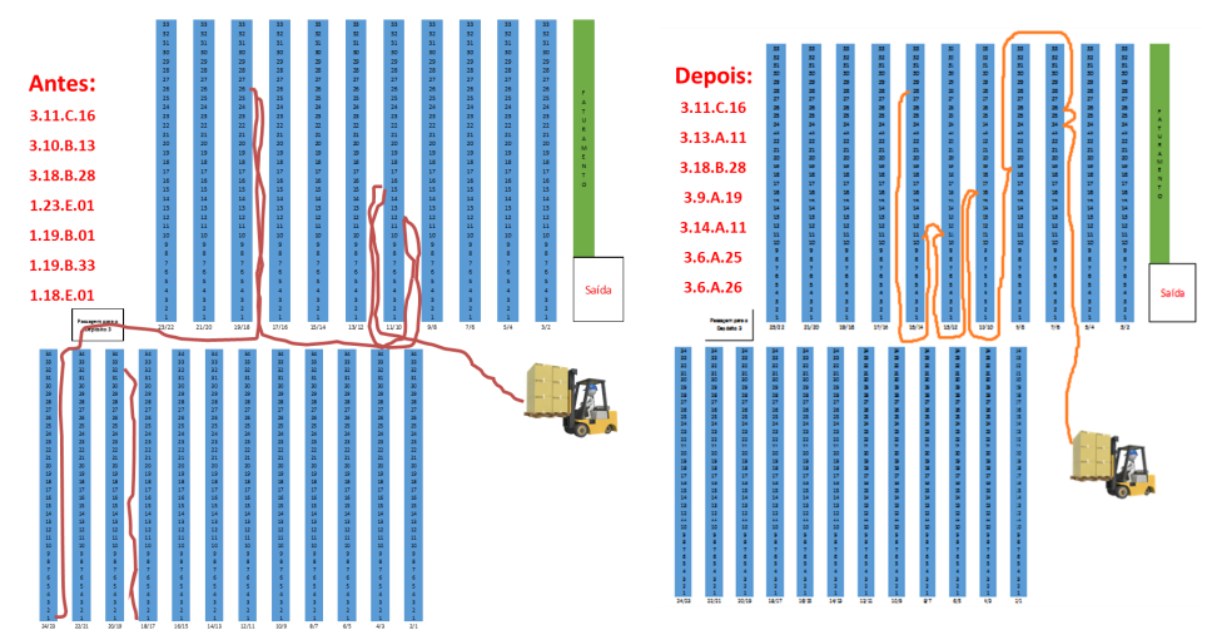

Fonte: Elaborado pela equipe do Kaizen 3P.

Foi revisada a instrução de trabalho das atividades de armazenagem e abastecimento a fim de reciclar e treinar novos colaboradores destas atividades, para padronização do novo método adotado na organização do depósito.

Com a nova organização a meta é reduzir para $0,01 \%$ do volume total estocado (peças). As peças não localizadas decorrentes da falta e/ou mapeamento errado são acompanhadas através do indicador de acuracidade do estoque, o qual aponta a quantidade de peças que foi dada baixa no sistema sobre o volume total armazenado no último dia do mês. Hoje a empresa tem $0,0028 \%$ como meta, porém com uma redução de $20 \%$ a.a. O último apontamento mensal foi de $0,0023 \%$. Para medir o ganho de produtividade da equipe de separação, foi feita a cronoanálise da atividade com o depósito organizado por giro de SKU e será refeita assim que o depósito finalizar a organização por produtos de mesma família. Até o momento temos $25 \%$ do estoque organizado e a equipe de separação já teve um ganho de $20 \%$ de produtividade.

Para a gerência e diretoria acompanharem o desenvolvimento do projeto, um A3 foi desenvolvido, como mostrado na figura 11, contendo as seguintes informações: contexto do projeto com as situações pré-kaizen, análise das causas, estado futuro, plano de ação e medidas de acompanhamento.

Nota-se frequentemente sendo discutido na literatura sobre a importância da organização interna dos estoques e materiais em geral, para que se possa obter agilidade e aumento de confiabilidade e entrega aos clientes, sejam internos ou externos, e isso foi constatado neste estudo em questão. 
Figura 11 - A3 do Kaizen 3P

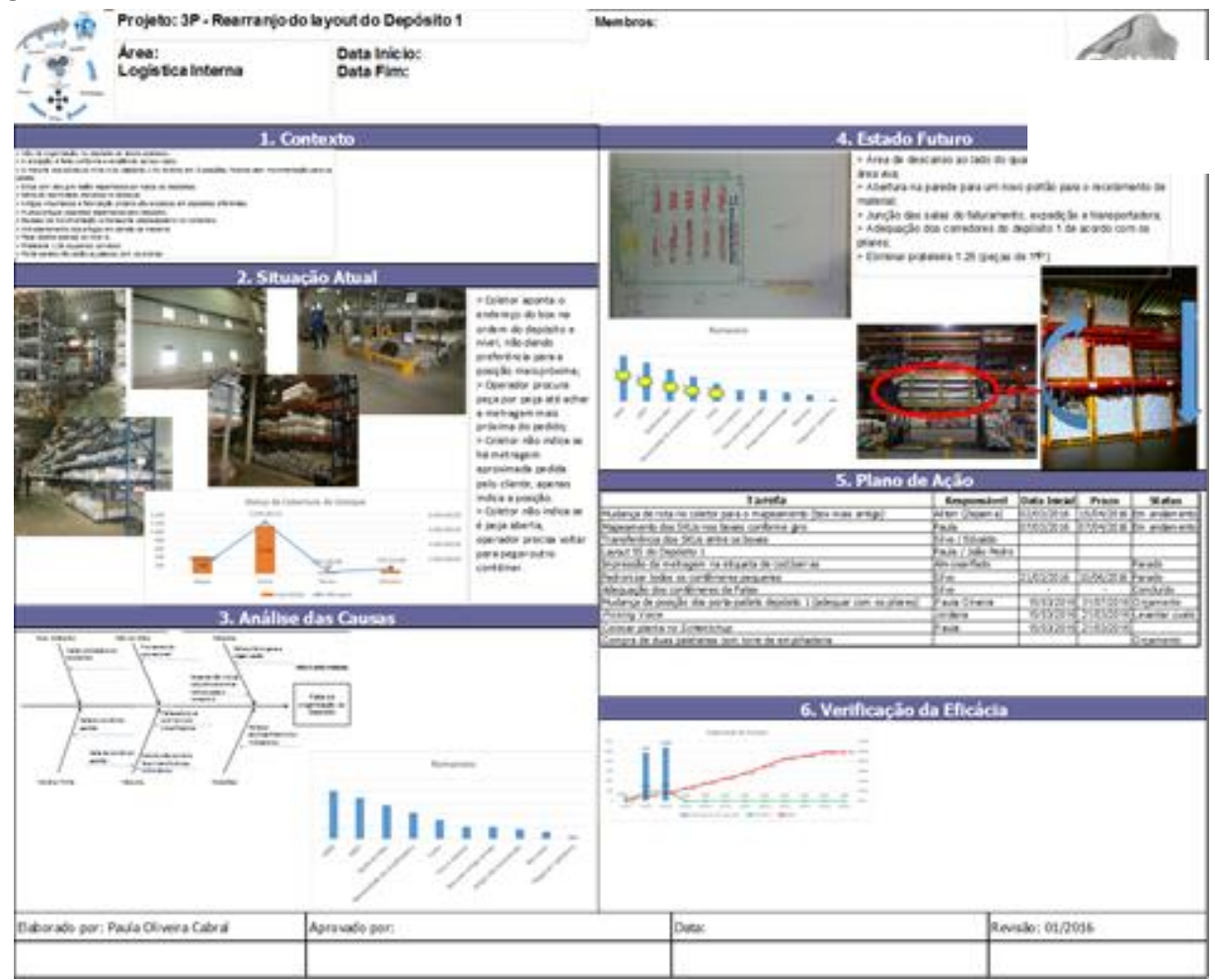

Fonte: Relatório Interno da Empresa.

\section{CONCLUSÕES}

$\mathrm{O}$ estudo utilizando a técnica do $3 \mathrm{P}$ e a organização do depósito com o agrupamento dos produtos por família, junto com a curva $A B C$, mostrou o quanto ainda é possível melhorar as atividades de armazenagem, reposição e separação. O processo de organização ainda está em andamento pela equipe da logística interna, pois são 51 famílias para organizar contendo um total de 2.900 produtos diferentes para analisar a curva $A B C$, tendo, também, que organizar o FIFO de cada SKU, quando houver a necessidade.

Um dos problemas que a empresa tinha era a quantidade de SKUs versus a quantidade de vagas existentes no picking. Não seria possível armazenar um unitizador de cada SKU devido à falta de vagas no picking. Com a organização em andamento e muitas vagas ficando vazias no nível A, já está se detectando outra oportunidade de melhoria, atacar o excesso de estoque. Hoje tem-se vagas no picking para armazenar todos os SKUS que possuem alto giro todos os meses do ano, porém nem todos possuem estoques, em contrapartida, produtos que não têm necessidade de terem FIFO devido à baixa demanda, possuem estoque em excesso. Com os SKUs mapeados nas mesmas prateleiras que seus estoques, a atividade do inventário também fica mais simples.

Outro ponto positivo foi o aumento do nível de serviço de atendimento à produção. Todos os pedidos de separação de peças para estampar e calandrar (estampagem com uso de cilindros desenhados em alto relevos e gravados no tecido através de alta temperatura) são realizadas com menor tempo já que os produtos separados sempre são da mesma família, mudando apenas as cores. 
Por meio de todas as etapas realizadas pode-se considerar que os objetivos do trabalho foram atingidos, e dizer que a pesquisa contribuiu para que novas formas de reorganização de operações logísticas/de estocagem fossem realizadas. Apesar dos resultados apresentados, a gestão da armazenagem ainda necessita de acompanhamento e aprimoramento, através da atualização dos relatórios de faturamento, da curva $A B C$, verificando as novas necessidades para a equipe de separação e uso de kaizens como uma ferramenta de extrema importância para a melhoria contínua do setor. Como sugestão de trabalhos futuros, pode-se aplicar as etapas realizadas neste trabalho em organizações de outros setores, que também buscam otimizar sua forma de estocagem. 


\title{
Inventory organization with application of Kaizen 3P and the ABC Curve: a case study in a textile industry
}

\begin{abstract}
The purpose of this paper is to address the importance of stock management and warehousing through SKU organization criteria (Stock Keeping Unit), based on the ABC (Activity Based Costing) of each product. The application of this proposal in the company studied had as objective to ensure that the items of greater demand were always in the levels of storage that do not need the use of forklifts and stairs for the picking. For this study, several improvement projects were used, such as the 3P Kaizen (Production Preparation Process) that aims to increase productivity through studies of lean layouts, reclassification of the $A B C$ curve, suitability of the unitizers for storage of products with varied demands and suitability of pallet pallet heights.
\end{abstract}

KEYWORDS: Textile Industry. Inventory Management. Kaizen 3P. ABC Curve. 


\section{REFERÊNCIAS}

ABIT - Associação Brasileira da Indústria Têxtil e de Confecções. Disponível em < http://www.abit.org.br/cont/dados-comercio-exterior > Acesso em 23/07/2017.

AGUIAR, T. A. S.; JÚNIOR, D. S. G. Aumento da eficiência através da reestruturação do arranjo físico: estudo em uma empresa do setor gráfico. 2018. ABEPRO Associação Brasileira de Engenharia de Produção. Disponível em <http://www.abepro.org.br/biblioteca/TN_STO_258_482_35716.pdf> . Acesso em 08/02/2019.

ANDRADE, G. J. P. O.et al. Um método de diagnóstico do potencial de aplicação da manufatura enxuta na indústria têxtil. 2006. UFSC - Universidade Federal de Santa Catarina. Disponível em <https://repositorio.ufsc.br/bitstream/handle/123456789/88970/236945.pdf?seq uence $=1>$. Acesso em 24/05/2017.

BITTENCOURT, T. H. G; ACCIOLY, R. C. Estudo do balanceamento da carga de trabalho no processo de armazenagem da produção em área de picking. 2017. ABEPRO - Associação Brasileira de Engenharia de Produção. Disponível em <http://www.abepro.org.br/biblioteca/TN_STO_238_379_34364.pdf >. Acesso em 08/02/2019.

CORRÊA, H. L.; CORRÊA, C A. Administração de Produção e Operações Manufatura e Serviços: uma abordagem estratégica. São Paulo: Atlas, 2004, 690 p.

CORRÊA, H. L.; GIANESI, I. G. N.; CAON, M. Planejamento, programação e controle da produção. São Paulo: Atlas, v. 1, 2001.

DORIGUEL, F.; TEIXEIRA, C. A. Manufatura Enxuta: Melhoria contínua de produtividade utilizando a filosofia Kaizen $3 \mathrm{P}$ em uma empresa de grande porte na cidade de Botucatu. Tekhne e Logos, v. 6, n. 1, p. 13-25, 2015.

DOS SANTOS, A. M.; RODRÍGUEZ, I. A. Controle de estoque de materiais com diferentes padrões de demanda: estudo de caso em uma indústria química. Gestão \& Produção, v. 13, n. 2, p. 223-231, 2006. crossref

GAVIOLI, G.; SIQUEIRA, M. C. M.; SILVA, P. H. R. Aplicação do programa 5s em um sistema de gestão de estoques de uma indústria de eletrodoméstico e seus impactos na racionalização de recursos. Unidade Berrini da FGV: SIMPOI, 2009.

GORINI, A. P. F. Panorama do setor têxtil no Brasil e no mundo: reestruturação e 
perspectivas. BNDES Setorial, Rio de janeiro, n. 12, 2000.

GOTEX SHOW - Feira Internacional de Produtos Têxteis. Disponível em <http://gotexshow.com.br/mercado/> Acesso em 23/07/17.

GRANDO, M. L.; BUENO, S. A.; WANDSCHEER, G. L.; ANCHAU, C. Análise de gestão de estoques de reposição em uma empresa de médio porte em Nonoai/RS. 2018. ABEPRO - Associação Brasileira de Engenharia de Produção. Disponível em <http://www.abepro.org.br/biblioteca/TN_STP_258_481_36506.pdf> Acesso em 05/02/2019.

KON, A.; COAN, D. C. Transformações da indústria têxtil brasileira: a transição para a modernização. Revista de Economia Mackenzie, v. 3, n. 3, 2009.

LIMA, M. P. Os custos de armazenagem na logística moderna. 2000. Disponível em < http://professorricardo.tripod.com/Artigo_13.pdf $>$. Acesso em 24/05/2017.

NISHIDA, L. Logística Lean: conceitos básicos. Lean Institute, 2006. Disponível em < http://www.lean.org.br/artigos/41/logistica-lean-conceitos-basicos.aspx>. Acesso em 24/07/2017.

PALONIMO, R.; SILVEIRA, R. O.; OLIVEIRA, R.; MOURA, T.; SANTANA, L. O. Aplicação da curva abc na gestão de estoque de uma microempresa de Aracaju/SE. 2018. ABEPRO - Associação Brasileira de Engenharia de Produção. Disponível em <http://www.abepro.org.br/biblioteca/TN_STP_258_480_35928.pdf >. Acesso em 08/02/2019.

RIBEIRO, J.O. R. et al. (UNIFRAN). Análise da alteração do arranjo físico na perspectiva dos sete desperdícios: um estudo de caso em uma montadora de implementos agrícolas. 2016. ABEPRO - Associação Brasileira de Engenharia de Produção. Disponível em <http://www.abepro.org.br/biblioteca/TN_STP_226_320_30748.pdf>. Acesso em 25/05/2017.

SILVA, T. G. E.; SILVA, M. C. S.; GARCIA, N. S. C.; ALMEIDA, L. F. M. Produção enxuta: conceitos, características e aplicação de ferramentas em uma empresa de panificação. 2018. ABEPRO - Associação Brasileira de Engenharia de Produção. Disponível em <http://www.abepro.org.br/biblioteca/TN_STO_258_478_35392.pdf>. Acesso em 08/02/2019.

TORRES JUNIOR, A. S. 3P - Passaporte para a "Universidade" do Sistema Toyota 
de Produção. Lean Institute Brasil, 2005. Disponível em <http://www.lean.org.br/comunidade/artigos/pdf/artigo_76.pdf >. Acesso em 24/07/2017.

ZAMCOPÉ, F. C. et al. Modelo para avaliar o desempenho de operadores logísticos: um estudo de caso na indústria têxtil. Gestão \& Produção, v. 17, n. 4, p. 693-705, 2010.

Recebido: 04 mai. 2018

Aprovado: 14 fev. 2019

DOI: $10.3895 /$ gi.v15n1.8258

Como citar:

CHAGAS, P. O. C.; LOOS, M. J. Organização do estoque com aplicação do Kaizen 3P e da Curva ABC: um estudo de caso em uma indústria têxtil. R. Gest. Industr., Ponta Grossa, v. 15, n. 1, p. 64-85, jan./mar. 2019. Disponível em: <https://periodicos.utfpr.edu.br/rgi>. Acesso em: XXX.

Correspondência:

Paula Oliveira Cabral Chagas

Avenida Elvíirio Mário Mancini, 1149, Vila Nova, 79602-020, Três Lagoas, Mato Grosso do Sul, Brasil. Direito autoral: Este artigo está licenciado sob os termos da Licença Creative Commons-Atribuição 4.0 Internacional.

(c) (i) 